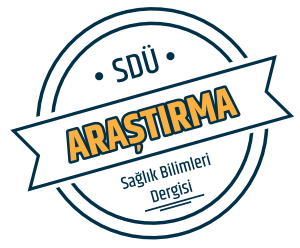

Sdü Sağlık Bilimleri Enstitüsü Dergisi / Cilt 9 Sayı 2 / 2018

\title{
Ağız Diş Çene Cerrahisinde Sedasyon Uygulamaları ve Diş Çekimlerinin Retrospektif Olarak Değerlendirilmesi
}

\section{A Retrospective Analysis of Sedation and Tooth Extractions in Oral Maxillofacial Surgery}

Müge Çına Aksoy ${ }^{1}$, Hatice Akpınar ${ }^{1}$

${ }^{1}$ Süleyman Demirel Üniversitesi Diş Hekimliği Fakültesi Ağız Diş Çene Cerrahisi Ad.Isparta, Türkiye

\section{Özet}

Amaç: Diş Hekimliği'nde diş tedavilerinin birçoğunun lokal anestezi ile yapılmasına rağmen kooperasyon eksikliği, cerrahiye uyumsuzluk ve anksiyete veya tıbbi komplikasyonların bir sonucu olarak sedasyona ihtiyaç duyulmaktadır. Retrospektif olarak planlanan bu çalışmanın amacı sağlıklı çocuk hastalarda, sedasyon ile yapılan diş çekimlerinin değerlendirilmesidir.

Materyal-Method: Çalışmada, 15 aylık süreçte, tek bir merkezde, sedasyon ile diş çekimi yapılan çocuk hastaların dosyaları retrospektif olarak değerlendirildi. Çalışmaya dahil edilme kriterlerine uyan, 2-18 yaş arasında, 1088 hastanın verilerine ulaşıldı.

Bulgular: Çalışmaya dahil edilen toplam 1088 çocuk hastadan 2848 diş çekimi yapılmıştır. Hastaların yaş ortalaması 6,23 olarak bulunmuştur. Hastaların \%42'si kız, \%58'i erkektir. Hastalar, yaş aralıklarına göre 3 grupta değerlendirilmiştir. Buna göre, hastaların \%57,8'inin 2-6 yaş grubunda, \%40,4'ünün 7-11 yaş grubunda, \%1,8'inin 12-18 yaş grubunda olduğu tespit edildi. Hastaların \%97,4'ünde inhalasyon ile sedasyon yapılmış olup bu hastalarda kişi başı ortalama 2,56 diş çekimi yapılmışken; iv sedasyon yapılan hastalarda $(\% 2,6)$ ortalama çekim sayısının 4,75 olduğu bulunmuştur.

Sonuç: İzole süt dişi çekimlerinin planlandığı, 11 yaş altı günübirlik çocuk hastalarda azotprotoksit+oksijen ve gerekli olduğu durumlarda sevafluran desteği yapılarak inhalasyon yöntemi ile sedasyon yeterli ve güvenli anestezi sağlamaktadır.

Anahtar kelimeler: Çocuk, Diş çekimi, Sedasyon.

\begin{abstract}
Objective: Despite the fact that most dental treatments are performed with local anesthesia in dentistry, sedation is preferred as a result of lack of co-operation, surgery incompatibility and anxiety or medical complications. The purpose of this retrospective study is to evaluate tooth extraction with sedation in healthy children.
\end{abstract}

Material-Method: In the study, the data of pediatric patients who had tooth extraction with sedation were evaluated retrospectively in a single center for 15 months. Data from 1088 patients between the ages of 2 and 18, meeting the inclusion criteria, were included.

Results: A total of 1088 children were included in the study and 2848 teeth were extracted. The average age of the patients was found to be 6.23 . $42 \%$ of the patients were female and $58 \%$ were male. Patients were evaluated in 3 groups according to their age range. It was determined that $57.8 \%$ of the patients were in the 2-6 age group, $40.4 \%$ in the $7-11$ age group and $1.8 \%$ in the $12-18$ age group. $97.4 \%$ of the patients were sedated with inhalation, and in these patients, an average of 2.56 teeth per child were extracted; IV sedation patients $(2.6 \%)$ had an average of 4.75 teeth per child.

Conclusions: In the case of children under 11 years of age, where the extraction of primary teeth is planned, the patient is provided with adequate and safe anesthesia with nitrous oxide and sevaflurane if necessary.

Keywords: Children, tooth extraction, sedation.

\section{Giriş}

Diş Hekimliği'nde diş tedavilerinin birçoğunun lokal anestezi ile yapılmasına rağmen kooperasyon eksikliği, cerrahiye uyumsuzluk ve anksiyete veya tıbbi komplikasyonların bir sonucu olarak sedasyon ve genel anesteziye ihtiyaç duyulmaktadır. Dental anksiyete bir çok değişkenden etkilenen kompleks bir durumdur. Çocuklardaki korku ve kayg1, ebeveynlerden ve çevreden kaynaklanan sosyokültürel faktörler, yaşanmış olumsuz diş hekimi deneyimleri gibi çeşitli nedenler ile ortaya çıkmaktadır (1).
DOI: $10.22312 /$ sdusbed. 444893

Müracaat tarihi: 18.07.2018

Kabul tarihi: 26.07.2018

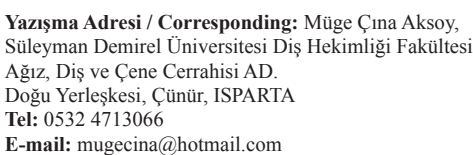


Diş hekimine ve diş tedavilerine karşı duyulan kaygı ve korku toplumda yaygın görülen bir sorundur. $\mathrm{Bu}$ sorunun klinikte aşılamadığı, orta seviyede zorluktaki ya da uzun süreli işlemlerde sedasyon uygulamaları alternatif olarak karşımıza çıkmaktadır. Literatürde çocuk hastalarda sedasyon ile diş çekimi gereksiniminin \%10-20 arasında olduğu bildirilmektedir (2). Son yıllarda diş tedavilerinde sedasyon uygulamalarında anlamlı artışın saptandığı bildirilmektedir (3).

Dental anksiyete ve diş hekimi korkusuna sahip çocuklarda rutin diş hekimi kontrolleri yapılamamakta ve çürük insidansı daha yüksek olmaktadır. Ayrıca, sadece diş ağrısı ve apse gibi acil durumlarda diş hekimine gidildiği için koruyucu diş hekimliği uygulama basamakları atlanmakta ve erken diş çekimlerinde artışa neden olmaktadır (4).

Genel anestezi işlemleri kendi içerisinde bilinçli sedasyondan, havayolunun mutlak suretle kontrol altına alınmasının zorunlu olduğu, solunumun tamamen gittiği tüm işlemleri kapsayan genel bir durumu ifade eder. İleri dental tedavilerin ve cerrahilerin planlanmadığı sadece diş çekimi yapılan, hava yolunu tehlikeye sokmayacak ve işlem süresinin 30 dakikayı geçmediği hastalarda fizyolojik reflekslerin korunduğu, hastanın fiziksel ve sözlü uyaranlara cevap verebildiği bilinçli sedasyon tercih edilmektedir $(4,5)$.

Retrospektif olarak planlanan bu çalışmanın amacı sağlıklı çocuk hastalarda sedasyon ile yapılan diş çekimlerinin değerlendirilmesidir.

\section{Materyal Metot}

$\mathrm{Bu}$ çalışma Diş Hekimliği Fakültesi Genel Ameliyathanesi'nde gerçekleştirildi. Çalışma için Tıp Fakültesi Klinik Araştırmalar Yerel Etik Kurulu'ndan onay alındı (04.07.2018 tarih ve 132 sayı).

Çalışmada,DişHekimliğiFakültesiGenelAmeliyathanesi'nde 1 Ocak 2017-31 Mart 2018 tarihleri arasındaki 15 aylık süreçte, sedasyon ile diş çekimi yapılan çocuk hastaların dosyaları retrospektif olarak değerlendirildi.

Çalışmaya dahil edilmeme kriterleri, Mental retardasyon, 2 yaş altı çocuk veya 18 yaş üstü yetişkin hastalar, hayati tehlike gösteren ileri düzeyde sistemik hastalığı olan hastalar (ASA4 (Amerikan Anesteziyoloji Derneği Preoperatif Fiziksel Durum Sinıflaması) ve üzeri) olarak belirlendi.

Çalışmaya dahil edilme kriterleri, 2-18 yaş arasında, sedasyon ile diş çekimi yapılmış, ASA1, ASA2 ve ASA3 skoruna sahip çocuk hastalar olarak belirlendi. Taranan hasta dosyalarından dahil edilme kriterlerine uyan 1088 hastanın verilerine ulaşıldı.

Hastaların yaş, cinsiyet, toplam çekilen diş sayısı, işlem süresi ve hangi dişlerinin çekildiği ve uygulanan sedasyon tekniği [inhalasyon ve intravenöz (iv)] ve hastaların ASA skorları Amerikan Anesteziyoloji Derneği Preoperatif Fiziksel Durum Sinıflamasına göre değerlendirildi ve kaydedildi (6) (Tablo 1).

Kliniğimizde sedasyon uygulamalarında, ameliyat odasına alınan hastalar ASA kılavuzuna göre monitörize edilerek, nabız, non-invaziv kan basıncı ve SpO2 değerleri, başlangıçta ve 5 dakika aralarla kontrol edilip kayıt altına alınmaktadır. Anesteziye bağlı oksijen düzeyleri \%90'ın altına indiğinde nazal CBAP (Continuous Positive Airway Pressure, Sürekli Pozitif Havayolu Basıncı) maske ile hastaların solunumu desteklenerek yeterli oksijenizasyon sağlanmaktadır. Inhalasyon yönteminde, hastalarda $\% 50$ Oksijen $+\% 50$ Azotprotoksit+1-8 MAC arasında hastanın ihtiyacına göre değişen dozlarda Sevorane (Sevofluran ${ }^{\circledR}$-AbbVie Tibbi İlaç San.Türkiye) ile anestezi yapılmıştır. Intravenöz anestezide ise, hastalara damar yolundan Propofol ${ }^{\circledR}$ Lipuro \%1 (10mg/ $\mathrm{ml}$ Propofol-Braun Medikal Türkiye) 'lik ilaçtan $1 \mathrm{mg} / \mathrm{kg}$ dozda bolus indüksiyon dozunu takiben $0,5 \mathrm{mg} / \mathrm{kg}$ dozda hasta ihtiyacına göre idame dozları yapılmıştır.

Hastalar yaş gruplarına göre 2-6, 7-11 ve 12-18 yaş olmak üzere 3 gruba ayrıldı. Her grupta yapılan diş çekimleri süt ve daimi diş olmalarına göre değerlendirildi.

\section{Bulgular}

Çalışmaya dahil edilen toplam 1088 çocuk hastadan 2848 diş çekimi yapılmıştır (kişi başı ort 2,6). Hastaların yaş ortalaması 6,23 (2-15yaş ) olarak bulunmuştur.

Çalışmaya dahil edilen toplam 1088 çocuk hastanın cinsiyete göre dağılımı değerlendirildiğinde hastaların \%42'si (n=457) kız, \%58'i ( $n=631)$ erkektir. Toplam hasta sayılarının ve diş çekimlerinin cinsiyete göre dağılımları Şekil 1'de verilmiştir. Yaş gruplarına göre hastalar incelendiğinde çalışmaya dahil edilen hastaların \%57,8'inin 2-6 yaş grubunda $(n=629)$, $\%$ 40,4'ünün 7-11 yaş grubunda $(\mathrm{n}=440), \% 1,8$ 'inin $12-18$ yaş grubunda $(n=19)$ olduğu tespit edilmiştir. Yaş gruplarına göre yapılan diş çekimi sayılarının dağılımı Şekil 2'de verilmiştir. Çekilen dişlerin yaş gruplarına göre dağılımı incelendiğinde

Tablo 1. ASA(Amerikan Anesteziyoloji Derneği) preoperatif fiziksel durum sınıflandırması

\begin{tabular}{l|l} 
ASA Derecesi & Hasta \\
\hline ASA1 & Sağlıklı Hasta \\
\hline ASA2 & Hafif bir sistemik bozukluğu olan hasta \\
\hline ASA3 & Aktivitesini sınırlayan ancak güçsüz bırakmayan sistemik bozukluğu olan hasta \\
\hline ASA4 & $\begin{array}{l}\text { Gücünü tamamen yitirmesine neden olan, hayatına sürekli tehdit oluşturan sistemik bozukluğu olan } \\
\text { hasta }\end{array}$ \\
\hline ASA5 & 24 saatten fazla yaşaması beklenmeyen, ölüm halindeki hasta \\
\hline ASA6 & Organ donörü olmaya uygun, beyin ölümü gerçekleşmiş hasta
\end{tabular}


2-6 yaş grubunda en fazla çekilen dişlerin süt keser dişler olduğu $(\% 43,1), 7-11$ yaş grubunda süt 1.premolar dișler olduğu $(39,9)$ ve 12-18 yaş grubunda molar dişler olduğu $(42,4)$ tespit edilmiştir. Çalışmada sedasyon ile diş çekimi yapılan hastaların \%51,4’ü 2-6 yaş grubunda yer almaktadır. Yaş gruplarına göre kişi başına düşen ortalama diş çekimi sayısı en fazla 7-11 yaş grubunda bulunmuştur (ort 3,07). Hastalarda sedasyon ile diş çekimi süreleri ortalama 7,07 dak'dir (Tablo 2).

Çalışmaya dahil edilen sedasyon ile diş çekimi yapılan hastaların, sedasyon şekli ve ASA skorlarına göre işlem süreleri ve ortalama çekim sayıları Tablo 3'de verilmiştir. Buna göre hastaların \%97,4'ünde inhalasyon ile sedasyon yapılmış olup bu hastalarda kişi başı ortalama 2,56 diş çekimi yapılmışken; iv sedasyon yapılan hastalarda $(\% 2,6)$ ortalama çekim sayısının 4,75 olduğu bulunmuştur. İşlem sürelerine bakıldığında, inhalasyon ile sedasyon yapılan hastalarda işlem süresi ortalama 6,95 dak iken iv sedasyon uygulanan hastalarda 11,46 dak olduğu görülmüștür. Ayrıca çalışmaya dahil edilen hastaların \%98'inin operasyon öncesi değerlendirmede ASA1 skoruna sahip olduğu görülmüştür. Hastaların hiç birinde anesteziye bağlı komplikasyon görülmemiştir.

Tablo 2. Çekilen dişlerin, kişi başına düşen ortalama diş çekimi sayısının ve ortalama işlem süresinin yaş grupların göre dağılımı (\%).

\begin{tabular}{|c|c|c|c|c|c|c|c|c|c|c|}
\hline \multirow{2}{*}{$\begin{array}{l}\text { Yaş } \\
\text { Grupları }\end{array}$} & \multicolumn{4}{|c|}{ Süt Dişleri } & \multicolumn{3}{|c|}{ Daimi Dişler } & \multirow{2}{*}{$\begin{array}{l}\text { Toplam Çekim } \\
\text { say1s1 (\%) }\end{array}$} & \multirow{2}{*}{$\begin{array}{l}\text { Diş Çekimi } \\
(\text { Ort })\end{array}$} & \multirow{2}{*}{$\begin{array}{l}\text { Çekim Süres } \\
\text { (Dak.,Ort) }\end{array}$} \\
\hline & Keser Diş & Kanin & Süt IV & Süt V & Keser & Premolar & Molar & & & \\
\hline 2-6 Yaş & 43,1 & 2,9 & 35,2 & 18,3 & - & - & 0,5 & 51,4 & 2,33 & 6,72 \\
\hline 7-11 Yaş & 17,2 & 9,8 & 39,9 & 29,6 & 0,1 & 0,2 & 3,2 & 47,5 & 3,07 & 7,54 \\
\hline 12-18 Yaş & - & 15,2 & 9,1 & 30,3 & - & 3,0 & 42,4 & 1,2 & 1,74 & 7,47 \\
\hline Toplam & 30,3 & 6,4 & 37,1 & 23,8 & 0,1 & 0,1 & 2,2 & 100 & 2,62 & 7,07 \\
\hline
\end{tabular}

Tablo 3. Sedasyon şekline ve ASA skorlarına göre ortalama yaş, işlem süresi ve hastalarda çekilen ortalama diş sayıları

\begin{tabular}{l|l|l|l|l|l} 
& & Hasta sayısı n (\%) & Yaş & İşlem süresi (ort. dak.) & Çekim sayısı (ort) \\
\hline \multirow{2}{*}{ Sedasyon } & İnhalasyon & $1060(97,4)$ & 6,17 & 6,95 & 2,56 \\
\cline { 2 - 6 } & IV sedasyon & $28(2,6)$ & 8,53 & 11,46 & 4,75 \\
\hline \multirow{2}{*}{ ASA Skoru } & ASA1 & $1067(98)$ & 6,21 & 7,06 & 2,6 \\
\cline { 2 - 6 } & ASA2 & $17(1,5)$ & 6,94 & 6,9 & 3,11 \\
\cline { 2 - 6 } & ASA3 & $4(0,5)$ & 8,75 & 9,25 & 3,75 \\
\hline \multirow{2}{*}{ Toplam } & 1088 & 6,23 & 7,07 & 2,62 & \\
\end{tabular}

Şekil 1. Toplam hasta ve çekilen diş sayısının cinsiyete göre dağılımı

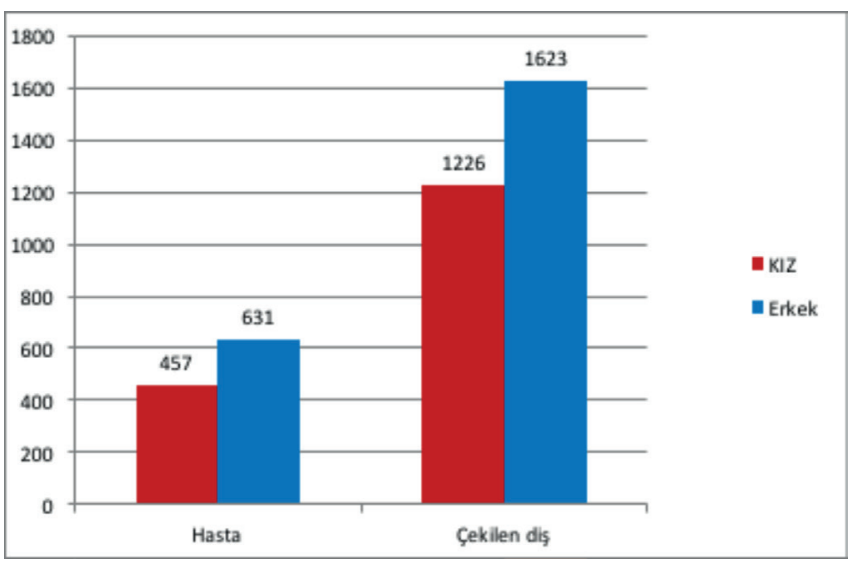

Şekil 2. Toplam hasta ve çekilen diș sayısının yaş gruplarına göre dağılımı

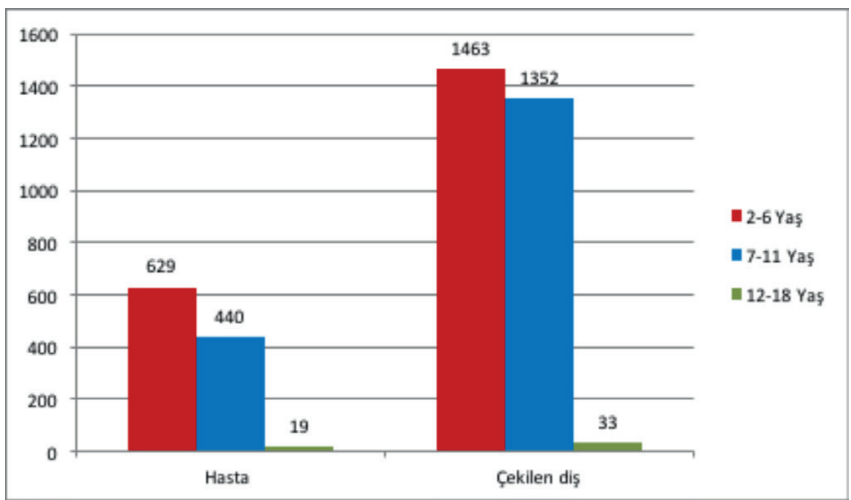




\section{Tartışma}

Dental anksiyete, hastaların dental tedavi öncesinde, tedavi sırasında veya her iki aşamada ortaya çıkabilen, pek çok değişkenden etkilenen, kompleks bir olgudur (1, 7). Çürük insidansının yüksek olması, düzenli diş hekimi kontrollerinin yapılmaması, geçmiş kötü tecrübeler gibi faktörler anksiyeteyi arttıran sebeplerdir $(1,8)$. Ağrı dental anksiyeteye neden olmakla birlikte mevcut anksiyeteyi arttırıcı rol oynamaktadır (9).

Yapılan çalışmalarda toplumda diş hekimi korkusu ve anksiyeteye sahip çocuk hastaların oranı yaklaşık \%3-43 olarak rapor edilmektedir (10). Bu oranın 2-6 yaş arası çocuk hastalarda \%30 civarında olduğu, yaşın büyümesi ile azaldığı gösterilmiştir. Yedi yaş ve sonrasında dental anksiyetenin azaldığı ve çocukların korkuları ile başa çıkabildiği rapor edilmektedir (4). Sedasyon ile diş çekimi yapılan hastaların retrospektif olarak değerlendirildiği çalışmamızda hastaların \%57,8'i 2-6 yaş grubunda yer almakta, çalışmaya dahil edilen toplam 1088 hastanın yaş ortalaması 6,23'dür ve literatür ile uyumludur.

Literatürde pek çok çalışmada, erkek çocuklarda kız çocuklarına oranla daha yüksek seviyede dental anksiyete eğilimine rastlandığı rapor edilmektedir $(4,11)$. Diğer taraftan yüksek kayg1 düzeylerine kızlarda daha fazla rastlandığını rapor eden çalışmalar da mevcuttur (12). Bizim çalışmamızda da sedasyon ile diş çekimi yapılan hastaların \%58'ini erkek çocuklar oluşturmaktadır. Ancak çalışmaya dahil edilme kriterlerine uygun kısıtlı sayıda hastanın dahil edilmesinin bu sonuca etkisi olabilir ve daha uzun süreli retrospektif analizlerin yapılabildiği geniş hasta grupları ile yapılacak çalışmalara ihtiyaç vardır.

Dental anksiyeteye sahip çocuklarda çürük insidansının yüksek olduğu yapılan çalışmalarda bildirilmektedir. Aynı zamanda çürük diş sayısının fazla olmasının ve ağrının dental anksiyeteyi arttırdığ 1 belirtilmektedir (1, 4, 8, 13). $\mathrm{Bu}$ hastalarda koruyucu diş hekimliği uygulamalarının yapılamaması sonucu ağrı ve enfeksiyonların kontrolü için acil tedaviler ve diş çekimlerine ihtiyaç duyulmaktadır. Çalışmamızda daimi molar diş çekimlerinin 2-6 yaş grubunda $\% 0,5,7-11$ yaş grubunda $\% 3,2$ ve $12-18$ yaş grubunda $\% 42,4$ olduğu tespit edilmiştir. Literatürde 4-6 yaş grubunda $\% 0,9,7-12$ yaş grubunda $\% 5,7$ ve $13-18$ yaş grubunda $\% 5,6$ oranında sedasyon ile daimi diş çekimi rapor edilmiştir (14). Diğer bir çalışmada 6 yaş üstü sağlıklı çocuklarda sedasyon ile daimi diş çekimlerinin 6 yaş altı çocuklara göre istatistiksel olarak anlamlı oranda yüksek olduğu bildirilmiştir (15). Sonuçlarımız genel olarak literatür ile uyumluluk göstermektedir. 12-18 yaş grubundaki daimi molar diş çekim sayısındaki farklılığın çalışmalardaki yaş grupları arasındaki farktan ve hastaların sosyoekonomik düzey farklılığından kaynaklanmış olabileceği kanaatindeyiz.

Sarı et al. (14) 64 sağlıklı çocuk hastada dental genel anestezi ile toplam 127 diş çekimi yapıldığını ve kişi başı ortalama diş çekimi sayısının en yüksek 7-12 yaş grubunda (ort. 3,64) olduğunu bildirmişlerdir. Chen et al. (15) 2017 y1lında yaptıkları retrospektif çalışmalarında, 3-6 yaş grubunda sedasyon ile süt dişi çekimlerinin kişi başı ortalama 2,08 olduğunu ve 6 yaş üstü çocuklara göre istatistiksel olarak yüksek olduğunu rapor etmişlerdir. Çalışmaları 20062015 yılları arasında 10 yıllık bir periyodu içermekte olup sedasyon ile süt dişi çekimlerinin 2011 yılından itibaren arttığını belirtmişılerdir. Sunulan çalışmada kişi başı ortalama diş çekimi 2,62 (1-11diş)' dir. Diş çekimi sayıları en yüksek 7-11 yaş grubunda (ort 3,07)'dır ve 2-6 yaş grubunda ise ortalama 2,33 olduğu bulunmuştur, genel literatür ile uyumludur. Diş tedavilerinde özellikle kooperasyon problemi yaşayan veya anksiyetesi olan sağlıklı çocuklar ve zihinsel engelli çocukların akut ve ağrılı diş tedavilerinde dental genel anestezi kullanımı artmaktadır. Literatürde 2014 ve 2015 yıllarında dental genel anestezi ile yapılan diş tedavilerinin 2006 ve 2007 yıllarındakilere göre 2 kattan daha fazla olduğu rapor edilmektedir (15). Çocuk hastaların velileri ile yapılan çalışmalarda, 1980'li yıllarda velilerin ses ile kontrol ve fiziksel kısıtlama ile tedaviyi tercih ettikleri; 1990'lı yılların başından itibaren sedasyonun veliler tarafindan daha tercih edilebilir olduğunu; 2005 y1lından sonra ise sedasyon ve genel anestezinin veliler tarafindan, fiziksel kısitlama ile tedaviye göre daha kabul edilebilir olduğunu göstermektedir (15).

Pek çok hastada dental işlemlerin meydana getirdiği anksiyete, bilinç düzeyinin hafifçe baskılanması ile başarılı bir şekilde kontrol altına alınabilmektedir. Bilinçli sedasyon hastanın farmakolojik, farmakolojik olmayan veya kombine yöntemler ile bağımsız ve devamlı olarak havayolunu devam ettirebilecek şekilde, bilincin minimal düzeyde baskılanması, fiziksel uyaranlara ve sözlü komutlara anlamlı yanıt verebilmesi durumudur. Bilinçli sedasyon; oral, inhalasyon, intranazal, iv, intramusküler, rektal ve sublingual yolla uygulanabilmektedir (16). Azotprotoksit+oksijen, diş hekimliği uygulamalarında inhalasyon sedasyonunda en sık kullanılan ajandır. $\% 50$ azotprotoksit düzeyi aşılmadığ 1 sürece anestezinin 1. evresinde sedasyon düzeyi sağlanmakta ve 1 saat ve üzerinde devam edecek sedasyon seansları güvenle gerçekleştirilebilmektedir ancak güçlü analjezik etkisine rağmen düşük anestezik etkiye sahip olması nedeni ile tek başına, anksiyetesi yüksek hastalarda yetersiz kalabilmekte ve ilave ajanlar kullanılması gerekmektedir (4, 17). Sevafluran, düşük kan gaz çözünürlüğü, nedeniyle etkisi hızlı başlayan ve hızlı sonlanan, irritasyona neden olmayan bir inhalasyon ajanıdır. Sub-anestezik konsantrasyonda kullanıldığında kontrollü derin sedasyona izin vermektedir (18). Soldani et al. (10), azotprotoksit+oksijen ve azotprotoksit+oksijen+sevafluran karışımının çocuklarda diş tedavilerinin yapılması için güvenli ve etkili olduğunu bildirmişlerdir.

Propofol, etki süresi kısa, yan etkilerinin az olması ve erken ve kaliteli derlenme sağlanması nedeniyle günübirlik hastalarda iv bilinçli sedasyon için tercih edilen bir ilaçtır ve $0,25-1 \mathrm{mg} / \mathrm{kg}$ bolus ve $1-4 \mathrm{mg} / \mathrm{kg} / \mathrm{saat}$ infüzyon dozlarının sedasyon sağlamada yeterli olduğu bildirilmektedir (19, 20). Hava yolunu tehlikeye sokacak ve uzun süreli işlemler nedeniyle sedasyon için uygun olmayan hastalar genel anestezi prosedürüne tabi tutulmaktadır. Sedasyonda işlem 
süresi 20-30 dakikayı geçmemektedir. Sunulan çalışmaya izole diş çekimi yapılan hastalar dahil edilmiş olup, işlem süreleri inhalasyon yönteminde ortalama 6,95 , iv anestezide 11,46 dakikadır. Hastanın havayolu koruyucu refleksleri baskılanmadan, havayolunu sıkıntıya sokacak herhangi bir işleme izin verilmemeli, ayrıca her hasta her medikasyona aynı düzeyde cevap vermediğinden, işlem sedasyon olarak planlansa dahi genel anestezi için hazırlık yapılmalıdır. Sedasyonun efektif ve güvenilir kullanımı için uygun ekipman ve anestezi uzmanının kontrolünde, yapılacak işlem ve hastaya göre uygun sedatif ajan ve dozun seçilmesi gereklidir.

\section{Sonuç}

Çocukluk döneminde sık görülen dental anksiyete, diş tedavilerinin gerektiği zamanda yapılmasına engel olmakta ve acil tedavi gerektiren ağrılı durumlarda sedasyon ile tedavi ihtiyacını arttırmaktadır. Diş hekimi korkusu ve anksiyete nedeniyle sedasyon ihtiyacı en yüksek 2-6 yaş arası çocuk hastalarda karşımıza çıkmakta ve 7 yaş sonrasında azalmaktadır. İzole süt dişi çekimlerinin planlandı̆̆ 1,11 yaş altı günübirlik çocuk hastalarda azotprotoksit+oksijen ve gerekli olduğu durumlarda sevafluran desteği yapılarak inhalasyon yöntemi ile sedasyon yeterli ve güvenli anestezi sağlamaktadır. Daha büyük yaşlarda, komplike daimi diş çekimlerinde veya yüksek anksiyete düzeyine sahip çocuklarda ise propofol ile iv sedasyon kullanılabilmektedir.

\section{Kaynaklar}

1. Coolidge T, Irwin SP, Leyster KA, Milgrom P. Determinants of receiving intravenous sedation in a sample of dentallyfearful patients in the USA. SAAD Digest. 2012; 28: 52-60.

2. Holroyd I. Conscious sedation in pediatric dentistry. A short review of the current UK guidelines and the technique of inhalational sedation with nitrous oxide. Paediatr Anaesth. 2008; 18(1): 13-7.

3. Chicka MC1, Dembo JB, Mathu-Muju KR, Nash DA, Bush HM. Adverse events during pediatric dental anesthesia and sedation: a review of closed malpractice insurance claims. Pediatr Dent. 2012; 34(3): 231-8.

4. Arpaci AH, Isik B. Pediatric tooth extractions under sedoanalgesia. Pak J Med Sci. 2016; 32(5): 1291-1295.

5. Durmuş E. The Use of Sedation Midazolam for Dentistry. J Dental Sci-Special Topics. 2013; 4(3): 17-21.

6. Irlbeck T, Zwißler B, Bauer A. ASA classification: Transition in the course of time and depiction in the literatüre. Anaesthesist. 2017; 66(1): 5-10.

7. Armfield JM, Pohjola V, Joukamaa M, Mattila AK, Suominen AL, Lahti SM. Exploring the associations between somatization and dental fear and dental visiting. Eur J Oral Sci. 2011; 119: 288-93.
8. López-Jornet P, Camacho-Alonso F, Sanchez-Siles M. Assessment of general pre and postoperative anxiety in patients undergoing tooth extraction: a prospective study. Br J Oral Maxillofac Surg. 2014; 52(1): 18-23.

9. Zuniga JR. Guidelines for anxiety control and pain management in oral and maxillofacial surgery. J Oral Maxillofac Surg. 2000; 58(10): 4-7.

10. Soldani F, Manton S, Stirrups DR, Cumming C, Foley J. A comparison of inhalation sedation agents in the management of children receiving dental treatment: a randomized, controlled, cross-over pilot trial. Int J Paediatr Dent. 2010; 20(1): 65-75.

11. Kil HK, Kim WO, Han SW, Kwon Y, Lee A, Hong JY. Psychological and behavioral effects of chloral hydrate in day-case pediatric surgery: a randomized, observer-blinded study. J Pediatr Surg. 2012; 47(8): 1592-9.

12. Peretz B, Efrat J1. Dental anxiety among young adolescent patients in Israel. Int J Paediatr Dent. 2000; 10: 126-32.

13. Milsom KM, Tickle M, Humphris GM, Blinkhorn AS. The relationship between anxiety and dental treatment experience in 5-year-old children. Br Dent J. 2003; 194: 503-6.

14. Sari ME, Ozmen B, Koyuturk AE, Tokay U. A retrospective comparison of dental treatment under general anesthesia on children with and without mental disabilities. Niger J Clin Pract. 2014; 17: 361-5.

15. Chen YP, Hsieh CY, Hsu WT, Wu FY, Shih WY. A 10year trend of dental treatments under general anesthesia of children in Taipei Veterans General Hospital. J Chin Med Assoc. 2017; 80(4): 262-8.

16. Çağıran E, Özveri Koyuncu B, Sezer B. Dişhekimliğinde bilinçli sedasyonda intravenöz ajanlar. EÜ Dişhek Fak Derg. 2012; 33 (1): 1-5.

17. Önçağ Ö. Çocuk Diş Hekimliğinde Azot Protoksit/ Oksijen İnhalasyon Sedasyonu. Turkiye Klinikleri J Dental Sci-Special Topics. 2013; 4(3): 35-41.

18. Lahoud GY, Averley PA. Comparison of sevoflurane and nitrous oxide mixture with nitrous oxide alone for inhalation conscious sedation in children having dental treatment: a randomised controlled trial. Anaesthesia. 2002; 57(5): 44650 .

19. Arıboğan A, Oral U, Özbek N, Cobar E. Manyetik rezonans görüntülemede sedasyon amaciyla propofol uygulaması. Türk Anest ve Rean Cem Mecmuası. 1994; 22: 65-9.

20. Yüksel E, Efeoğlu C, Balcığlu ST. Çocuklarda sedasyon uygulamalarında güncel yaklaşımlar. Turkiye Klinikleri J Dental Sci-Special Topics. 2013; 4(3): 42-51. 